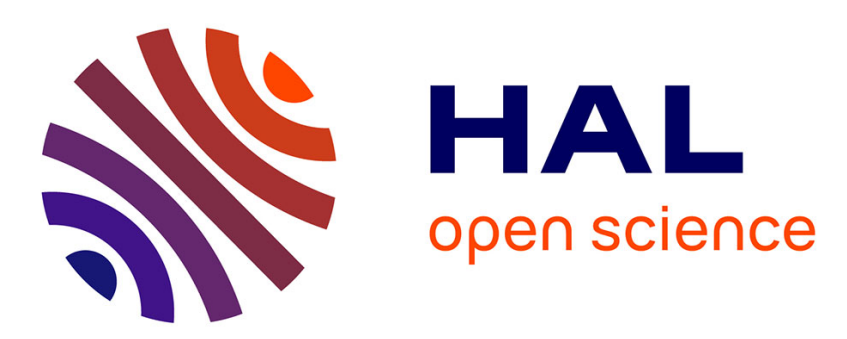

\title{
Global evaluation and sensitivity analysis of a physically based flow and reactive transport model on a laboratory experiment
}

Laure-An Gatel, Claire Lauvernet, Nadia Carluer, S. Weill, Julien Tournebize, Claudio Paniconi

\section{To cite this version:}

Laure-An Gatel, Claire Lauvernet, Nadia Carluer, S. Weill, Julien Tournebize, et al.. Global evaluation and sensitivity analysis of a physically based flow and reactive transport model on a laboratory experiment. Environmental Modelling and Software, 2019, 113, pp.73-83. 10.1016/j.envsoft.2018.12.006 . hal-02608419

\section{HAL Id: hal-02608419 \\ https://hal.inrae.fr/hal-02608419}

Submitted on 16 May 2020

HAL is a multi-disciplinary open access archive for the deposit and dissemination of scientific research documents, whether they are published or not. The documents may come from teaching and research institutions in France or abroad, or from public or private research centers.
L'archive ouverte pluridisciplinaire HAL, est destinée au dépôt et à la diffusion de documents scientifiques de niveau recherche, publiés ou non, émanant des établissements d'enseignement et de recherche français ou étrangers, des laboratoires publics ou privés. 


\title{
Global evaluation and sensitivity analysis of a physically based flow and reactive transport model on a laboratory experiment.
}

\author{
Laura Gatel $^{\mathrm{a}, \mathrm{d}, *}$, Claire Lauvernet ${ }^{\mathrm{a}}$, Nadia Carluer $^{\mathrm{a}}$, Sylvain Weill ${ }^{\mathrm{b}}$, Julien Tournebize $^{\mathrm{c}}$, Claudio Paniconi $^{\mathrm{d}}$ \\ ${ }^{a}$ Irstea, 5 rue de la Doua, CS 20244, 69625 Villeurbanne Cedex, France \\ ${ }^{b}$ Lhyges, 1 rue Blessing, 67084 Strasbourg, France \\ ${ }^{c}$ Irstea, 1 rue Pierre-Gilles de Gennes, 92761 Antony, France \\ ${ }^{d}$ INRS-ETE, Université du Québec, 490 rue de la Couronne, Quebec City G1K 9A9, Canada
}

\begin{abstract}
Spatialized physically based models are necessary tools for assessing the fate of pesticides in natural environments transfered by diffuse pollution. In this study the CATHY (CATchment HYdrology) model is coupled with reactive processes (adsorption and degradation). The resulting reactive subsurface component is evaluated on laboratory data by (i) comparing the model performance on experimental data using a combination of statistical criteria, (ii) conducting a Morris sensitivity analysis on both hydrological and solute transfer variables, and (iii) improving the CATHY model parameter settings based on the sensitivity analysis results. The sensitivity analysis produces a ranking of the factors wherein those that are particularly influential on water flow and reactive solute transfer emerge. These are found to be the saturated hydraulic conductivity, the retention curve parameters, and the sorption coefficient. After a calibration of influential parameters based on Morris sensitivity analysis, the results obtained are largely consistent with laboratory data.

Keywords: integrated surface-subsurface model, reactive solute transfer, Morris sensitivity analysis, experimental data, pesticides
\end{abstract}

\section{Highlights}

- The surface-subsurface model CATHY was extended to include reactive transport.

- The model is able to reproduce a tracer and pesticide laboratory experiment.

- Pesticide fluxes are primarily influenced by conductivity, porosity, and $K_{O C}$.

- Calibration subsequent to Morris sensitivity analysis improves model performance.

\footnotetext{
* Corresponding author

Email address: lau.gatel@gmail.fr (Laura Gatel)
} 


\section{Software availability}

The CATHY (CATchment HYdrology) has been developped firstly in the 1990s by Claudio Paniconi (claudio.paniconi@ete.inrs.ca, INRS-ETE, 490 rue de la Couronne, Québec G1K 9A9, CANADA) and Mario Putti (mario.putti@unipd.it, University of Padova, via Trieste 63, 35121 Padova, Italy). Matteo Camporese (matteo.camporese@unipd.it, University of Padova, via Trieste 63, 35121 Padova, Italy) and Stefano Orlandini (stefano.orlandini@unimore.it, University of Modena, via Pietro Vivarelli 10, 41125 Modena, Italy) also significantly took part in the project and settled the commonly used version of CATHY. The model is open source and available at the following adress : https://bitbucket.org/cathy1_0/. CATHY is written in FORTRAN 90 and runs easily under Linux or Mac OS, the user only needs a Fortran compiler and common libraries. The size of the code subroutines, input files and preprocessing files together does not exceed 20 Mo. Input and output files are text files and the corresponding documentation is available in the main subroutine of CATHY. Some outputs are produced in a .vtk format and can be visualised in 3D with the VisIt software.

\section{Introduction}

Contaminant transfer from agricultural fields to aquatic environments is recognized to be an important source of pollution of freshwater. This transfer results from a combination of complex processes interactions within a watershed that are not yet fully understood. These processes include advection, dispersion, degradation, and sorption of solutes. Spatialized physically based models are useful to describe interaction mechanisms, but their parameterization and evaluation are critical challenges, requiring representative databases that are not often available. In this paper, reactive processes are implemented in the CATHY model, a surface/subsurface 3D physically-based flow and transport model (Camporese et al., 2010, Weill et al., 2011). This new version will be tested on a detailed laboratory experiment including water and reactive/nonreactive solute transport measured at high frequency. The model's performance in a subsurface drainage context will be evaluated via a rigorous methodological approach including analysis of several criteria and a global sensitivity analysis.

Contaminants found in surface waters and groundwaters are highly linked to hydrology and surface/subsurface as sorption and degradation, depend not only on the chemical properties. For example, the available time for solute reactions can be drastically reduced when rapid flow occurs, which can lead to a significant transfer of pesticides toward surface waters (Müller et al. 2003, Rabiet et al., 2010). Moreover, the transfer of water and pesticides in the surface and subsurface domains of a watershed is also largely influenced by soil characteristics

Reflecting this complexity, many soil pesticide fate models exist that are valid at specific scales. At the plot scale, RZWQM (Ahuja et al., 1999; Malone et al., 2004), MACRO (Larsbo and Jarvis, 2003, 2005), HYDRUS 
(Simunek et al., 2005, 2008), CRACK-NP (Armstrong et al., 2000), and SIMULAT (Aden and Diekkrüger, 2000) are widely used and share some common features, such as preferential solute transport and reaction second objective of sensitivity analysis can be illustrated by the study of Zhou et al. (2012) using the HYDRUS 1D flow model applied on an agricultural experimental station. Through Morris sensitivity analysis, 8 of the 30 studied parameters were identified as irrelevant. Muma et al. (2014) performed a sensitivity analysis on the CATHY model at a micro catchment scale and identified the saturated conductivity as a key parameter

These are usually represented, respectively, by a linear or general Freundlich equation and by first order decay or as a simple function of temperature. In addition, some models take into account volatilization, heat flux, or root uptake (Kohne et al. 2009). These soil pesticide models, however, are usually based on simplified representations of the governing processes (e.g., one-dimensional vertical flow), and/or they also do not account for surface/subsurface interactions. Integrated surface-subsurface hydrological models (ISSHMs) such as CATHY (Camporese et al., 2010), HydroGeoSphere (Aquanty Inc. 2015), and ParFlow (Kollet and Maxwell, 2006) can be effective in simulating spatially distributed hydrological processes (Sebben et al., 2013 Kumar et al. 2013) and can be applied in a wide range of flow contexts (for example particular topography or landscape elements, spatially variable boundary conditions, etc.). These are rigorous and well-tested models, having undergone for instance several benchmarking trials (Maxwell et al., 2014, Kollet et al., 2017). However, the benchmark studies have thus far focused exclusively on flow processes. There is thus a need to start incorporating and assessing the transport, and especially reactive transport, component of ISSHMs. These models allow simulation of complex processes and require parameterizations and data that represent sources of error or bias. These errors need to be taken into account and controlled when running and interpreting simulations. In particular, both validation on field data and uncertainty and sensitivity analysis methods should be included in the diagnoses (Saltelli et al., 2008).

In water quality and hydrology, such sensitivity analyses aim generally at a deeper understanding of variability and process representation, or at model improvement by highlighting the influential parameters (Saltelli et al. 2008). The first goal can be illustrated with the physically based model of a vegetative filter strip, VFSMOD (Muñoz-Carpena et al. , 1999), where the water table was recently added to study interactions with infiltration (Muñoz-Carpena et al., 2017). This new version was evaluated through a sensitivity analysis to study the effect of the water table below a buffer strip on its efficiency to retain water, sediments, and pesticides. Both of the sensitivity analysis methods used in these studies, Morris and extended Fast, suggested significant interaction between saturated hydraulic conductivity and water table depth, and showed that the water table should be considered as a key hydrologic factor in buffer strips (Lauvernet and Muñoz Carpena, 2018). The regarding the volume exiting the catchment at the outlet. Finally, if a study aims at performance evaluation, sensitivity indices can be computed on comparison criteria with data instead of the model's ouput variability 
with respect to a parameter, such as the Nash Sutcliffe coefficient of Efficiency (NSE) (Nash and Sutcliffe, 1970) or the root mean square error (RMSE). The NSE is considered as a reliable measure for assessing the performance of a hydrologic model, however in some cases this single index is not sufficient to draw conclusions (Jain and Sudheer, 2008). A good practice is to combine NSE with another criterion, such as the RMSE (McCuen et al. 2006, Gupta et al. 2009), and if possible to take into account uncertainty and possible bias in the evaluation process (Ritter and Muñoz-Carpena, 2013).

Part of a model's evaluation process is based on its capacity to reproduce data. Therefore the evaluation quality is highly related to the database quality in terms of data quantity, variety, and accuracy. At the plot

scale, some studies are based on distributed (in space and time) field measurements that ensure a representative database. For example, Kampf and Burges (2007) used surface outflow, piezometric water levels, and volumetric water content measurements from an experimental hillslope to validate the HYDRUS-2D model. Other studies are based on laboratory experiments that have the advantage of being fully controlled: boundary and initial fonditions as well as soil characteristics are well-known. The Landscape Evolution Observatory (LEO) (Pangle et al. 2015), for instance, is a hillslope scale complex infrastructure allowing various controlled experiments for model validation. Scudeler et al. (2016a) reproduced an isotope tracer experiment from LEO with the CATHY model and compared simulation results with observed output flow and concentration responses. At a smaller scale and complexity, several experiments on MASHYNS (Paris, 2004), a homogeneous tile drained soil, provide a substantial and complete database on tracers and on a large range of reactive pesticide transfers.

The main objective of this study is to perform a robust evaluation of the CATHY model at the laboratory plot scale and to help gain a better understanding of reactive solute processes in the subsurface. Model simulations of the MASHYNS experiment will be evaluated through classical criteria combined with statistical analysis to achieve an uncertainty assessment associated to the model's evaluation. In parallel, a sensitivity analysis will be performed with the Morris method and will allow the identification of influential parameters and the sensitivity of five key outputs to them: water table recharge volume for flow, peak concentration and timing, breakthrough timing, and NSE on output mass flow for solutes. The last step consists in applying the optimal set of input parameters obtained from the Morris sensitivity analysis to other solutes from the MASHYNS dataset in order to evaluate this reduced calibration. These three steps are complementary to reaching a good understanding and evaluation of this ISSHM-class model to which a reactive transport component has been added. 


\section{Materials and methods}

\subsection{Model description}

\subsubsection{Variably saturated flow and advective-dispersive transport}

The CATHY (CATchment HYdrology) model (Camporese et al., 2010, Weill et al., 2011; Scudeler et al.

$2016 \mathrm{~b}$ ) is a 3D physically-based model for the simulation of surface and subsurface water flow and solute transport. In this study we used only the subsurface module of CATHY, described by the Richards and advection-dispersion equations:

$$
\begin{gathered}
S_{w} S_{s} \frac{\partial \psi}{\partial t}+\theta_{s} \frac{\partial S_{w}}{\partial t}=\nabla\left[K_{s} K_{r}\left(\nabla \psi+\eta_{z}\right)\right]+q_{s s} \\
\frac{\partial \theta C}{\partial t}=\vec{\nabla} \cdot(-\vec{U} C+D \vec{\nabla} C)+q_{t s s}
\end{gathered}
$$

where $t$ is time [T], $S_{w}$ is the water saturation [-] $\left(S_{w}=\frac{\theta}{\theta_{s}}\right), \psi$ is the pressure head [L], $\theta$ is the volumetric moisture content [-], $\theta_{s}$ is the saturated moisture content or porosity [-], $S_{s}$ is the aquifer specific storage $\left[\mathrm{L}^{-1}\right], \nabla$ is the gradient operator $\left[\mathrm{L}^{-1}\right], K_{s}$ is the saturated hydraulic conductivity $\left[\mathrm{LT}^{-1}\right], K_{r}$ is the relative conductivity $[-], \eta_{z}=(0,0,1), z$ is the vertical coordinate directed upward $[\mathrm{L}], q_{s s}$ is a source (positive) or sink (negative) term that includes the exchange fluxes from the surface to the subsurface $\left[\mathrm{L}^{3} \mathrm{~L}^{-3} \mathrm{~T}\right], C$ is the solute concentration $\left[\mathrm{ML}^{-3}\right], \vec{U}$ is the Darcy velocity vector $\left[\mathrm{LT}^{-1}\right], D$ is the tensor for both dispersion and diffusion $\left[\mathrm{L}^{2} \mathrm{~T}^{-1}\right]$, and $q_{t s s}$ is a solute mass source (positive) or sink (negative) term $\left[\mathrm{ML}^{-3} \mathrm{~T}^{-1}\right]$.

Equations (1) and (2) are solved on a 3D grid that is constructed from a surface discretization replicated vertically to form a $3 \mathrm{D}$ tetrahedral mesh. The vertical layers can be of varying thickness. Boundary conditions and atmospheric forcing can be dynamically prescribed. Numerically solving the advective-dispersive equation can be complex, in particular because its mathematical behavior changes from parabolic form for dispersion dominated problems to hyperbolic form for advection dominated problems (Rubio et al., 2008). The solution chosen for CATHY is a time-splitting technique combining flux limited finite volumes for advection and a classical finite element scheme for dispersion (Mazzia and Putti, 2005, Weill et al., 2011). In the scheme the transfer of concentration from nodes to tetrahedra between dispersion and advection can lead to numerical dispersion. Since in this study advective processes are dominant, the dispersion module of CATHY was not activated.

\subsubsection{Inclusion of a reactive transport component}

Reversible instantaneous equilibrium sorption and first order decay reactions were implemented in CATHY as part of this study. These processes are, respectively, represented as:

$$
K_{d}=\frac{C_{S}}{C} \quad \text { with } \quad K_{d}=K_{O C} F_{O C}
$$




$$
\frac{\partial C}{\partial t}=-\lambda C
$$

where $K_{d}$ is the equilibrium constant $\left[\mathrm{L}^{3} \mathrm{M}^{-1}\right], C_{S}$ and $C$ are the solute concentrations respectively in soil and water $\left(\left[\mathrm{MM}^{-1}\right]\right.$ and $\left.\left[\mathrm{ML}^{-3}\right]\right), K_{O C}$ is the soil organic carbon coefficient $\left[\mathrm{L}^{3} \mathrm{M}^{-1}\right], F_{O C}$ is the weight fraction

of organic carbon in soil $\left[\mathrm{MM}^{-1}\right]$, and $\lambda$ is the decay constant $\left[\mathrm{T}^{-1}\right]$, which is inversely proportional to the half-life of the decaying solute.

First order decay reactions are based on the assumption that $\lambda$ does not change with time. This is a strong hypothesis since it implies that soil temperature and water content do not significantly influence the degradation processes. Nonetheless equations 3 and 4 are known to represent correctly the major solute reactions in soils (Kohne et al. 2009) and present as well the advantage of keeping to a minimum the number of new parameters: only $K_{d}$ and $\lambda$ are introduced in this new version of CATHY. Just as with the key hydraulic parameters (saturated conductivity, porosity, and specific storage), the spatial variability of $K_{d}$ and $\lambda$ can also be represented in the model. Equations (3) and (4) are solved on volumes and implemented after advection, taking into account element concentration values produced by the advection computation. Adsorption is implemented first, because it is considered here to be an instantaneous reaction. Decay is implemented after advection and computed on the solute concentration in water, implying that the solute adsorbed on soil particles is assumed to not undergo degradation.

\subsection{Sensitivity analysis: the Morris method}

Different levels of sensitivity analysis can be used depending on the study objectives as well as the model and database characteristics. One-at-a-time (OAT) sensitivity analyses, consisisting in varying one input parameter while fixing the others, are the most intuitive and thus the most popular in hydrology and pesticide modeling (Persicani, 1996, Lenhart et al. 2002). However, although they are very simple to implement, they do not take into account the effect of interactions between parameters, and they provide information only very locally around the input parameter values. Global sensitivity analysis (GSA), on the other hand, aims to find the contribution of each input factor to the variance of the model output as well as the parameter interactions. However, as they are based on Monte-Carlo sampling, the large range of simulations implies a high computational cost. A good compromise between exhaustive results and computational cost is the elementary effects method adapted by Campolongo et al. (2007) from Morris (1991). This screening based approach is considered as a golden mean between one-at-a-time and global methods. It allows detection of the effects of input parameters on the studied output variable (linear effects, nonlinear effects, and interactions) by considering both the mean and variance of the elementary effects, but it gives only qualitative results. Its low computational cost makes it very attractive for large problems, and it has consequently been successfully applied in ISSHMs as an exploration tool (see Herman et al. (2013) for a review). Considering $p$ input 
parameters, the method consists in generating trajectories to explore the input hypercube of dimension $p$ in the most optimal way. Trajectories are generated per "level", i.e. regular sections of the hypercube in all its dimensions (for example using 4 levels means dividing each parameter range in quartiles). In practice, the user defines $l$ the number of levels, $\Delta$ the discretization length in each direction, and $r$ the total number of trajectories. $\Delta$ is often defined as $\frac{l}{2(l-1)}$ and $r$ should be superior to 10 (Campolongo et al. 2007). The total number of combinations, $N$, is defined by $N=r(p+1)$. Considering 8 parameters and 10 trajectories, the total number of parameter combinations is equal to 90 . This is very small compared to global methods such as Sobol (1990): with 8 parameters, between 5000 and 10000 runs would be necessary in a Sobol study.
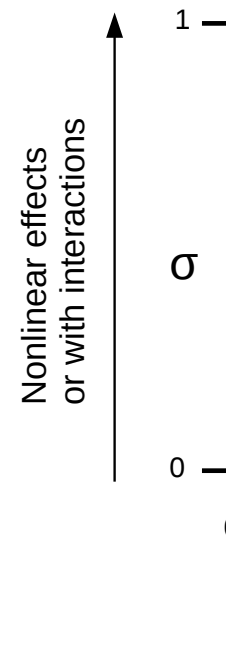

Nonlinear effects orland with interactions

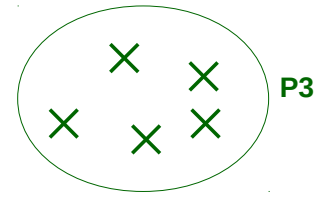

Linear effects

$\sigma \quad$ Negligible effects
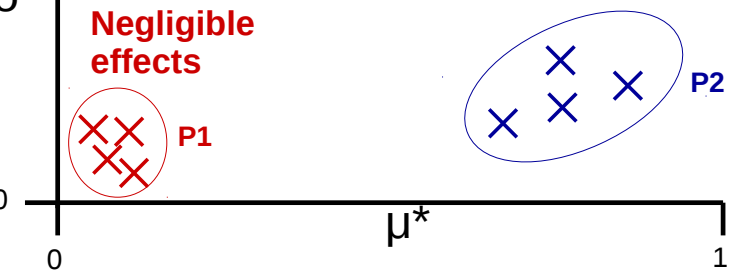

1

Major effects

Figure 1: Schematic interpretation of the effect of a group of parameters on a model output (indicated by X) in a Morris graph (adapted from Saltelli et al. (2004)).

After computation with all parameter combinations, the elementary effects mean and standard deviation for each parameter is calculated for the studied output variable and presented in a Morris graph, such as in Figure 1: the absolute mean $\mu^{*}$ in the horizontal axis reveals the influence of a parameter on the output variable and standard deviation $\sigma$ in the vertical axis provides information on nonlinear effects or interactions with other parameters. For example in Figure 1 the P2 parameter group has non negligible linear effects, the P3 parameters have non negligible effects with interaction or nonlinear effects, and the P1 parameter group has poor influence in both directions, meaning that its variations have little or no influence on model results. 


\subsection{The MASHYNS experimental model and the SSTM experiment}

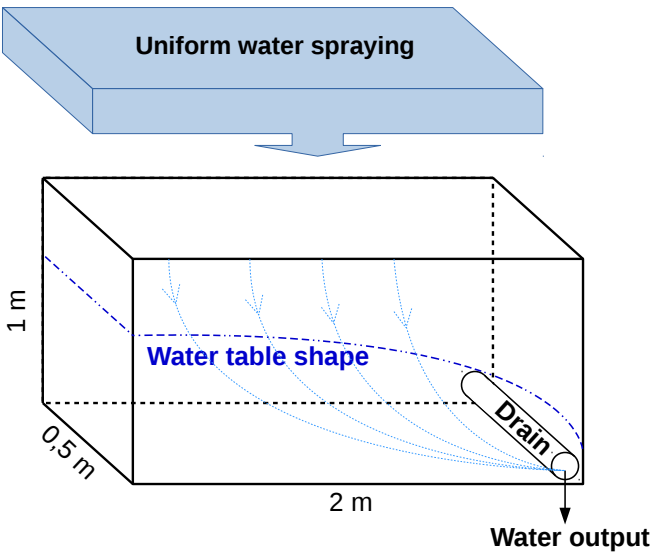

(a)

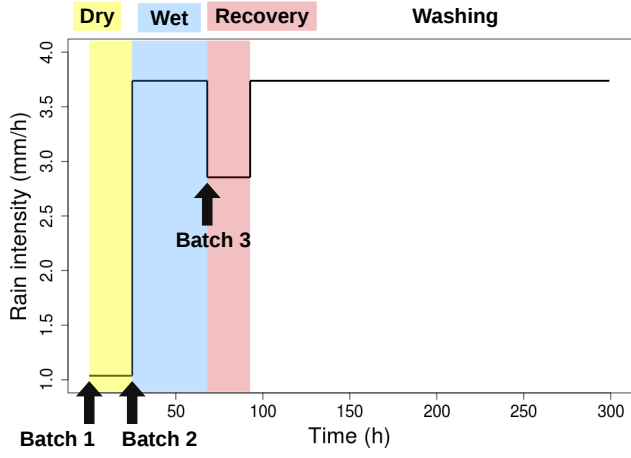

(b)

Figure 2: (a) The MASHYNS laboratory scale model. (b) Rainfall applied homogeneously on MASHYNS during the solute transfer experiment. Three batches of different solutes were introduced for one hour at $t=0, t=24 \mathrm{~h}$, and $t=72 \mathrm{~h}$, with different rain intensities.

In the subsurface solute transfer in MASHYNS (SSTM) experiment considered in this study, three representative hydrological conditions were generated by applying water inflow intensities corresponding, cumulatively, to a typical hydrological drainage season (equivalent to $250 \mathrm{~mm}$ of rain) (Figure 2b), and a longer fourth stage (200 h) was used to wash out the pesticides. The pesticide quantities applied were representative of farmer practices in a French drainage context (rape, wheat, maize). The characteristics of each of the four stages are summarized in Table 1 .

The monitoring strategy was based on leaching flux assessment. All drained water flows were sampled in $350 \mathrm{ml}$ glass flasks, collected by an ISCO automatic sampler. One out of three samples from stages 1 to 3 , and selected samples from stage 4, were sent for chemical analysis, corresponding to 150 samples. Detection limits for the six applied pesticides were below $0.005 \mu \mathrm{g} / \mathrm{l}$.

In the conditions of very low organic matter content and short tracer times that characterized the SSTM experiment, we can reasonably assume that no biotic degradation occurred, abiotic degradation (photolysis, 
Table 1: Characteristics of the four stages of the SSTM experiment.

\begin{tabular}{|l|l|l|l|l|}
\hline Stage & Dry (0-24h) & Wet (24h-72h) & Recovery (72h-103h) & Washing (103h-300h) \\
\hline \hline Season & summer & winter & spring & - \\
\hline Cumulative rain & $24 \mathrm{~mm}$ & $177 \mathrm{~mm}$ & $59 \mathrm{~mm}$ & $755 \mathrm{~mm}$ \\
\hline Water table & low & high & intermediate & high \\
\hline Tracers & amino-G & uranine & - & - \\
\hline Pesticides & $\begin{array}{l}\text { Batch 1: } \\
\text { clomazone } \\
\text { imazamox }\end{array}$ & $\begin{array}{l}\text { Batch 2: } \\
\text { mesosulfuron } \\
\text { isoproturon }\end{array}$ & $\begin{array}{l}\text { Batch 3 : } \\
\text { bentazone } \\
\text { sulcotrione }\end{array}$ & - \\
\hline
\end{tabular}

hydrolysis) could be neglected, and only hydraulic transfer and sorption processes were active.

\subsection{Model setup for the SSTM experiment}

Hydrological parameters considered in the flow simulation were: the horizontal and vertical saturated hydraulic conductivities $\left(K_{s h}\right.$ and $\left.K_{s v}\right)$, the porosity $\left(\theta_{s}\right)$, and the van Genuchten (1980) retention curve parameters $(n$ and $\alpha)$. Since MASHYNS is considered to be homogeneous, the same hydrological parameters are applied for each numerical layer. Saturated conductivities were measured three times, with a standard deviation described in section 3.2.1, and the mean value takes into account all the measurements. Retention curve parameters were assessed based on nine pressure measurements at various saturations. Two solutes per batch with contrasting properties (adsorption and degradation coefficients, see Table 2 ) were chosen. The equilibrium constant is expressed in the $K_{O C}$ form of equation (3), and $K_{d}$ values are thus the product of $K_{O C}$ from the pesticide properties database (Lewis et al. 2016) and the organic matter fraction in MASHYNS $(0.2 \%)$.

CATHY simulations are performed with atmospheric conditions (rainfall input) at the surface and with Dirichlet nodes set at atmospheric pressure head along one bottom edge of the domain to represent the drain (see Figure 3). All other boundary conditions are set to zero flux to represent the closed domain. Initial pressure in the domain represents a steady state of $1 \mathrm{~mm} / \mathrm{h}$ rain (obtained after 300 hours, the same duration as the SSTM experiment), and the initial concentration throughout the domain is zero. The surface mesh is discretized into $10 \times 40$ uniform cells of $5 \mathrm{~cm} \times 5 \mathrm{~cm}$ resolution, and is projected vertically to $1 \mathrm{~m}$ depth discretized into 16 layers of uniform thickness. The 3D mesh is composed of 7667 nodes and 12800 tetrahedral elements. 


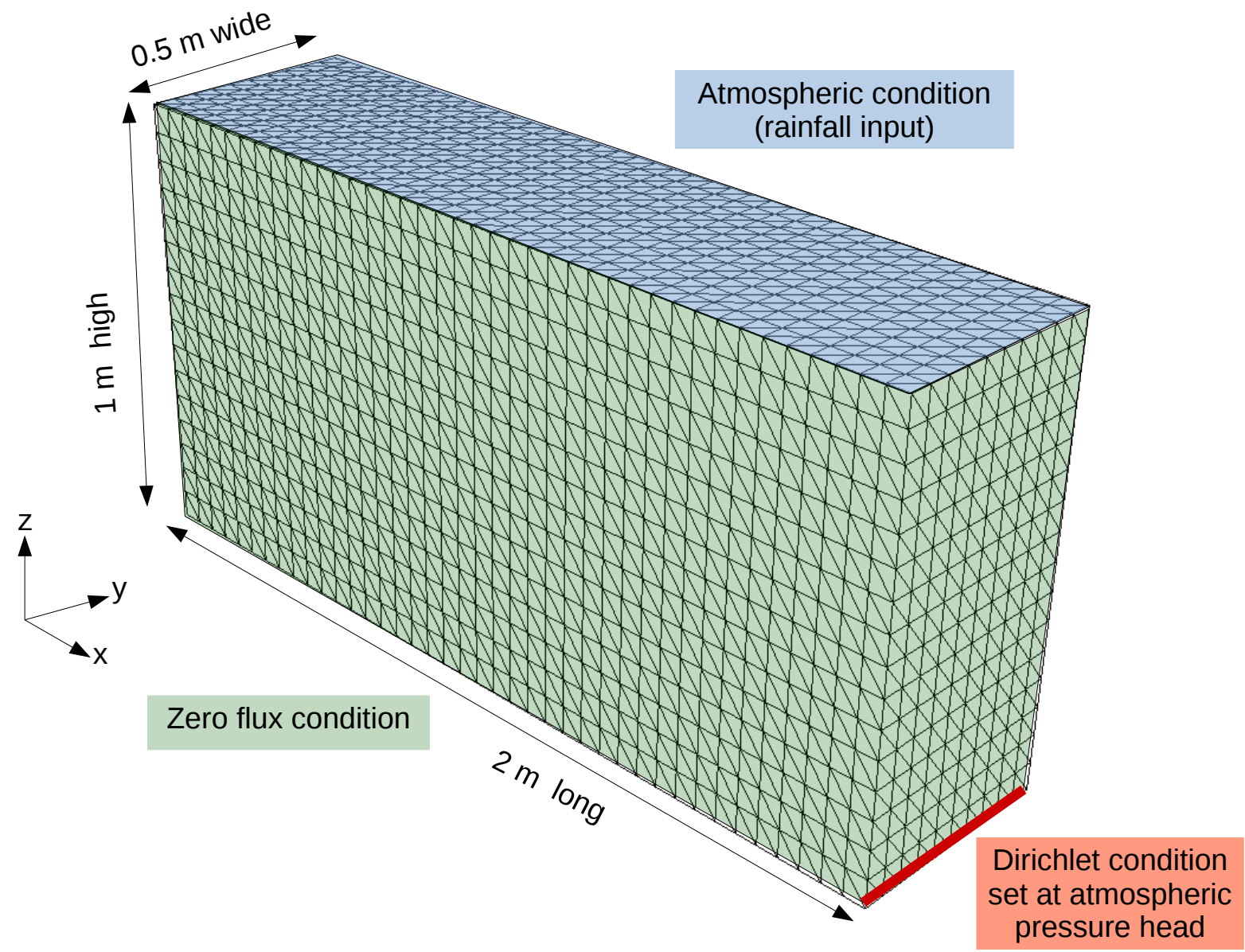

Figure 3: 3D mesh of the simulated domain with applied boundary conditions for the CATHY model $($ mesh: $5 \mathrm{~cm} * 5 \mathrm{~cm}$ and 16 soil layers).

Table 2: Half-life and equilibrium constant for the six studied solutes. All values were extracted from the pesticide properties database (Lewis et al. 2016) except ${ }^{(*)}$, which was obtained from the pesticide active ingredient database from Cornell University (http://pmep.cce.cornell.edu/profiles/index.html).

\begin{tabular}{|c|c|c|c|}
\hline & Solute & Half-life $T_{\frac{1}{2}}(\mathrm{~d})$ & Equilibrium constant $K_{O C}\left(\mathrm{~m}^{3} \mathrm{~g}^{-1}\right)$ \\
\hline \hline \multirow{3}{*}{ Batch 1 } & clomazone & 89 & 300 \\
\cline { 2 - 4 } & imazamox & 70 & $15^{(*)}$ \\
\hline \hline \multirow{3}{*}{ Batch 2 } & isoproturon & 12 & 122 \\
\cline { 2 - 4 } & mesosulfuron & 45 & 92 \\
\hline \hline \multirow{3}{*}{ Batch 3 } & bentazone & 45 & 55 \\
\cline { 2 - 4 } & sulcotrione & 25 & 36 \\
\hline
\end{tabular}




\subsection{Input parameters and output variables for sensitivity analysis}

The selection of model outputs for sensitivity analysis will depend on the objectives of the study and on the specific analysis method to be used. Fluxes in the unsaturated zones are more complex to simulate than fluxes in the saturated zone and are strongly dependent on the hydrological soil parameters. Water table recharge fluxes, i.e., fluxes from the unsaturated zone passing to the saturated zone, are a way to analyze the hydrological responses in the unsaturated zone. Concerning solute transfers, the output mass flow is a relevant output for assessing the solute transfer dynamic through the entire domain. To complete the model's output variables, four integrative variables connected to the breakthrough curve were added to the sensitivity analysis: timing of the solute concentration peak, concentration peak value, breakthrough timing (defined as the time when concentration reaches $5 \%$ of its peak value), and NSE value on the output mass flow $(\mathrm{g} / \mathrm{s})$.

\subsection{Model performance evaluation}

Hydrological and water quality models should be evaluated with methods that consider both accuracy and precision (Harmel et al., 2014). Typically, the NSE, which is commonly applied in hydrological studies, is very sensitive to extreme values, and to the number of data points. It is necessary to combine it with methods that consider bias, extreme values, and outliers. FITEVAL (Ritter and Muñoz-Carpena, 2013) is an evaluation method that combines 2 indicators, the NSE and the RMSE, and derives their approximated probability distributions by bootstrapping. The advantage of this proposed methodology is that it provides not only a criteria deterministic value but also statistics on the model evaluation. The performances are given with a goodness-of-fit evaluation represented by probability ratings: Unsatisfactory (NSE under 0.65), Acceptable (NSE from 0.65 to 0.80), Good (NSE from 0.80 to 0.90), and Very good (NSE above 0.90). Hence, the resulting detailed overview of model performance reduces modeler subjectivity. The NSE probability distribution for each evaluation and each simulation is given in the supplemetary materials (Table 8).

The subsurface part of the CATHY model version adapted for solute transport will be evaluated with respect to hydrology and reactive solute transport on the MASHYNS experimental apparatus following three successive steps. First, initial model performance will be evaluated on simulations without optimization, using the available measured parameters as input. Performance will be computed on two tracers and two solutes per batch (see Figure 2b based on comparison of the observed and simulated ouptut mass flow. The second step consists in a sensitivity analysis performed with the Morris method on the two solutes of batch 1 (clomazone and imazamox) and the two solutes of batch 2 (isoproturon and mesosulfuron). Eight parameters related to hydrology and solute transfer will be considered (see Table 6) and the analysis of various outputs will allow the identification of influential and interactive parameters. In a third step, the Morris analysis will allow selecting in the sampling the optimal parameter sets for the four solutes of batch 1 and batch 2 . This parameter set will be applied on the two solutes of the third batch, and NSE will be computed on the output solute mass of each simulation to get an idea of the simulation performance. 


\section{Results}

\subsection{Initial model performance on the SSTM experiment}

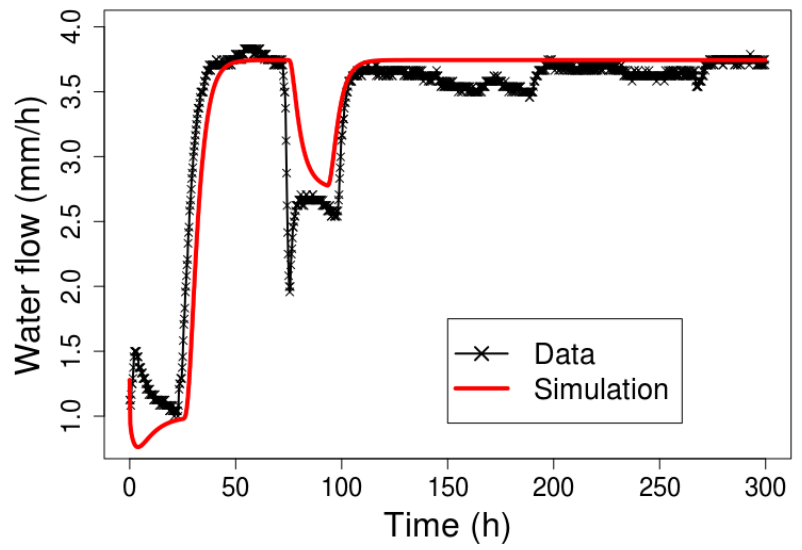

(a)
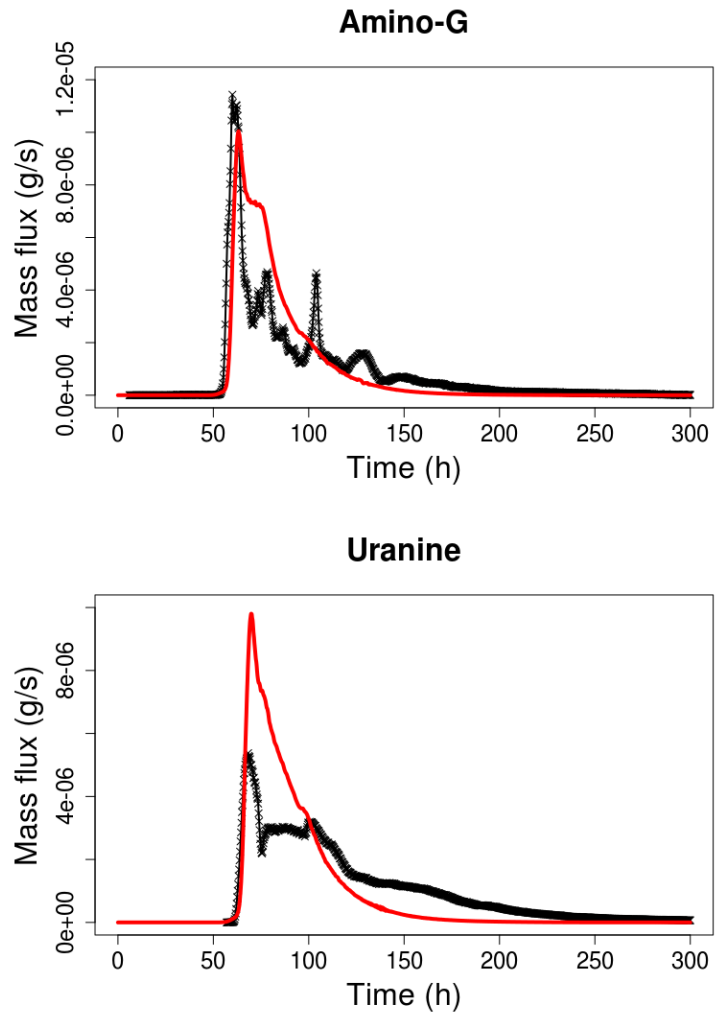

(b)

Figure 4: Water and nonreactive solute fluxes in the SSTM experiment: (a) water outflow; (b) solute outflow shown as a mass flow for the amino-G (batch 1) and uranine (batch 2) tracers.

For nonreactive solute transport, the mass flow is shown for two tracers: amino-G for batch 1 and uranine for batch 2 (Figure $4 \mathrm{~b}$ and Table 3). Both tracer simulations show a very accurate breakthrough timing. The mass flow peak is higher in simulation than in observation for uranine, with a sharper mass flow curve decrease. In the observations and simulations the breakthrough timing is nearly the same for the tracers of batch 1 and 
Table 3: Performance of the water and nonreactive solute fluxes simulation in the SSTM experiment (95\% confidence intervals in brackets).

\begin{tabular}{|c|c|c|}
\hline & NSE & RMSE \\
\hline Water flow & $0.78[0.350-0.915]$ & $0.346[0.189-0.502]$ \\
\hline Amino-G & $0.553[0.105-0.837]$ & $1.2 e^{-6}\left[4.7 e^{-7}-1.9 e^{-6}\right]$ \\
\hline Uranine & $-0.01[-0.781-0.672]$ & $1.2 e^{-6}\left[5.3 e^{-7}-1.9 e^{-6}\right]$ \\
\hline
\end{tabular}

Table 4: Performance of the reactive solute fluxes simulation in the SSTM experiment (95\% confidence intervals in brackets).

\begin{tabular}{|c|c|c|c|}
\hline & & NSE & RMSE \\
\hline \multirow{3}{*}{ Batch 1 } & Clomazone & $-39.90[-916--2.1]$ & $1.4 e^{-6}\left[8.6 e^{-7}-1.9 e^{-6}\right]$ \\
\cline { 2 - 5 } & Imazamox & $-0.05[-1.41-0.55]$ & $2.2 e^{-6}\left[1.1 e^{-6}-3.2 e^{-6}\right]$ \\
\hline \multirow{2}{*}{ Batch 2 } & Mesosulfuron & $0.32[-0.34-0.52]$ & $8.1 e^{-7}\left[6.2 e^{-7}-9.4 e^{-7}\right]$ \\
\cline { 2 - 5 } & Isoproturon & $-1.56[-6.22-0.19]$ & $1.1 e^{-6}\left[6.5 e^{-7}-1.5 e^{-6}\right]$ \\
\hline \multirow{2}{*}{ Batch 3 } & Bentazone & $-1.81[-5.32--0.28]$ & $2.5 e^{-6}\left[1.6 e^{-6}-3.5 e^{-6}\right]$ \\
\cline { 2 - 5 } & Sulcotrione & $-1.31[-2.3--0.45]$ & $3.0 e^{-6}\left[2.1 e^{-7}-3.7 e^{-6}\right]$ \\
\hline
\end{tabular}

batch 2 , respectively around $55 \mathrm{~h}$ and $60 \mathrm{~h}$. This indicates that the flow during the dry period doesn't contribute much to the solute transfer. The NSE computed for Amino-G is just below the Acceptable limit (the probability of fit being Unsatisfactory is $76.7 \%$ and $19.9 \%$ of being Acceptable), as the NSE computed for Uranine is clearly Unsatisfactory, due to the misfit between simulated and observed concentration peak. The uncertainty of the evaluation criteria NSE and RMSE (values in brackets) is quite large for the three results, and shows that the computed goodness-of-fit indicators are highly variable along the entire experiment timeline.

The solute breakthrough is delayed for the six reactive products except for mesosulfuron. Since the tracers did not exhibit this same inaccuracy, it may be that the $K_{d}$ values are optimal or appropriate. The calculation of $K_{d}$ from $K_{O C}$ may not be adapted to cases where the organic matter rate is very low. For example the generally neglected soil minerals contribution to sorption may be non negligible when the organic matter rate is very low (Sheng et al. 2001). NSE results are largely Unsatisfactory (with probabilities of fit of almost $100 \%$ for all solutes), which is not surprising considering the delay between observation and simulations. Mesosulfuron, which is the solute with shortest delay, show more encouraging NSE values. Despite a poor mathematical evaluation, the increasing and decreasing portions of the mass flow curves are well represented even while shifted by the delay.

Table 5 reports the experimental and simulated mass balances for each studied solute, calculated as the ratio between the initial mass put into the system and the cumulative mass that has exited the system at the end of the simulation. As implemented, the adsorption is reversible thus after the washing stage the total 

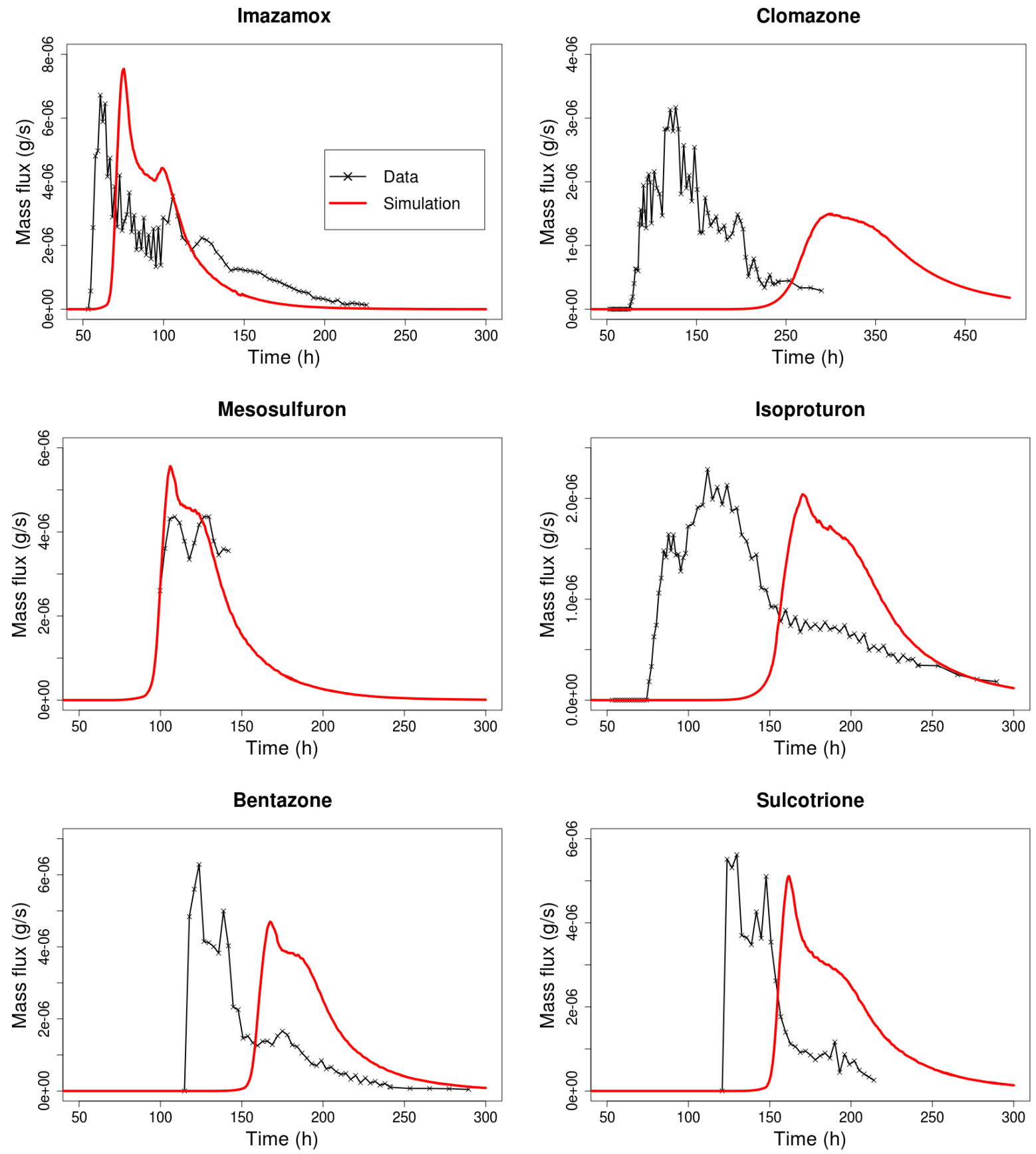

Figure 5: Reactive solute fluxes in the SSTM experiment. (a) Mass flow for clomazone and imazamox (batch 1), mesosulfuron and isoproturon (batch 2), and bentazone and sulcotrione (batch 3)

amount of input mass has theoretically exited the domain. Clomazone and bentazone show less than $10 \%$ variation between data and simulations, at $4 \%$ and $1 \%$ respectively. The mass balance variation for imazamox is the higher, at $33 \%$. The mesosulfuron results can be explained by the lack of data. Isoproturon, with a $21 \%$ mass variation, is the only solute whose total output simulated mass is markedly smaller than the measured 
Table 5: Mass balance for the six simulated reactive solutes. The column recovery represents the ratio between the initial mass put into the system and the cumulative mass that has exit the system at the end of the simulations.

\begin{tabular}{|c|c|c|c|c|c|}
\hline \multirow{2}{*}{ Solute } & Initial mass & \multicolumn{2}{|c|}{ Experiment } & \multicolumn{2}{c|}{ Simulation } \\
\cline { 3 - 6 } & $(\mathrm{g})$ & Mass $(\mathrm{g})$ & Recovery (\%) & Mass (g) & Recovery (\%) \\
\hline \hline Clomazone & $9.0 e^{-5}$ & $8.4 e^{-5}$ & 93 & $8.7 e^{-5}$ & 97 \\
\hline Imazamox & $1.0 e^{-4}$ & $5.7 e^{-5}$ & 57 & $9.0 e^{-5}$ & 90 \\
\hline \hline Isoproturon & $6.9 e^{-4}$ & $4.8 e^{-4}$ & 69 & $3.3 e^{-4}$ & 48 \\
\hline Mesosulfuron & $7.0 e^{-6}$ & $4.6 e^{-6}$ & 62 & $6.0 e^{-6}$ & 86 \\
\hline \hline Bentazone & $1.42 e^{-3}$ & $1.13 e^{-3}$ & 80 & $1.12 e^{-3}$ & 79 \\
\hline Sulcotrione & $2.3 e^{-4}$ & $1.6 e^{-4}$ & 68 & $1.95 e^{-4}$ & 85 \\
\hline
\end{tabular}

one. This may be because it is the only solute whose half-life (12 days) is close to the experiment duration (12.5 days).

\subsection{Morris sensitivity analysis}

\subsubsection{Probability density functions for the model inputs}

Input parameter probability density functions for sensitivity analysis should be based on scientific literature, data, or expert judgment (Saltelli et al., 2005). Because of the homogeneity of the soil in MASHYNS, the number of tested parameters is quite low. Eight parameters are taken into account: horizontal and vertical saturated hydraulic conductivity $\left(K_{s h}\right.$ and $\left.K_{s v}\right)$, retention curve parameters $(n$ and $\alpha)$, porosity $\theta_{s}$, input flow, equilibrium constant $K_{O C}$, and solute decay constant $\lambda$. All parameters, including the horizontal and vertical saturated conductivities, vary independently in the Morris method and are described by their probability density functions (see Table 6).

The saturated conductivity is commonly represented by a lognormal distribution (Coutadeur et al. 2002, Paris, 2004, Fox et al. 2010, Schwen et al., 2011) and the standard deviation is often taken to be equal to the mean when there is no information on its value (Muñoz-Carpena et al., 2010). In this work, the mean values of the vertical and horizontal saturated conductivities were chosen to satisfy three conditions: (i) that the measured anisotropy ratio is respected; (ii) that all measured conductivity values are covered by the distribution; and (iii) that the expected value is high enough to exclude all non representative behavior, in particular water saturation and overflow due to low $K_{s}$ value. The porosity and retention curve parameters follow a normal distribution, with a coefficient of variation of $10 \%$ according to Schwen et al. (2011) and Alletto et al. (2015). The rain intensity conditioning the initial steady state is not usually considered in sensitivity analysis; in this work we represented it as a uniform distribution with a $100 \%$ variation coefficient. The decay is considered to follow a normal distribution with a $20 \%$ coefficient of variation, based on Boivin (2003), Holvoet 
Table 6: Morris sensitivity analysis parameters with probability density function described by the mean $\mu$ and variance $\sigma^{2}$ (LN $=$ lognormal, $\mathrm{N}=$ normal, $\mathrm{U}=$ uniform, $\mathrm{T}=$ triangular $)$.

\begin{tabular}{|c|c|c|c|c|}
\hline Parameter & & Unit & \multicolumn{2}{|c|}{ Probability distribution } \\
\hline Horizontal saturated conductivity & $K_{s h}$ & $\mathrm{~ms}^{-1}$ & \multicolumn{2}{|c|}{$\mathrm{LN}(9 \mathrm{e}-05,1.39 \mathrm{e}-8)$} \\
\hline Vertical saturated conductivity & $K_{s v}$ & $\mathrm{~ms}^{-1}$ & \multicolumn{2}{|c|}{$\mathrm{LN}(5.62 \mathrm{e}-5,5.43 \mathrm{e}-9)$} \\
\hline Porosity & $\theta_{s}$ & - & \multicolumn{2}{|c|}{$\mathrm{N}(3.0 \mathrm{e}-1,9.0 \mathrm{e}-4)$} \\
\hline $\mathrm{VC}$ noromotor & $n$ & - & \multicolumn{2}{|c|}{$\mathrm{N}(1.8,3.24 \mathrm{e}-2)$} \\
\hline G parameters & $\alpha$ & $\mathrm{m}^{-1}$ & \multicolumn{2}{|c|}{$\mathrm{N}(1.2 \mathrm{e}-2,1.44 \mathrm{e}-6)$} \\
\hline Initial rain & $\mathrm{IC}$ & $\mathrm{ms}^{-1}$ & \multicolumn{2}{|c|}{$\mathrm{U}(2.7 \mathrm{e}-7,2.6 \mathrm{e}-2)$} \\
\hline \multirow{2}{*}{ Decay constant } & \multirow{2}{*}{$\lambda$} & \multirow{2}{*}{$\mathrm{s}^{-1}$} & $\begin{array}{c}\text { clomazone } \\
\mathrm{N}(1.30 \mathrm{e}-7,6.76 \mathrm{e}-16)\end{array}$ & $\begin{array}{c}\text { imazamox } \\
\mathrm{N}(1.65 \mathrm{e}-7,1.09 \mathrm{e}-15)\end{array}$ \\
\hline & & & $\begin{array}{c}\text { isoproturon } \\
\mathrm{N}(9.65 \mathrm{e}-7,3.7 \mathrm{e}-14)\end{array}$ & $\begin{array}{c}\text { mesosulfuron } \\
\mathrm{N}(2.57 \mathrm{e}-7,2.64 \mathrm{e}-15) \\
\end{array}$ \\
\hline \multirow{2}{*}{ Equilibrium constant } & \multirow{2}{*}{$K_{O C}$} & \multirow{2}{*}{$\mathrm{m}^{3} \mathrm{~g}^{-1}$} & $\begin{array}{c}\text { clomazone } \\
\mathrm{T}(139,300,608)\end{array}$ & $\begin{array}{c}\text { imazamox } \\
\mathrm{T}(5,15,143)\end{array}$ \\
\hline & & & $\begin{array}{c}\text { isoproturon } \\
\mathrm{T}(36,122,241)\end{array}$ & $\begin{array}{l}\text { mesosulfuron } \\
\mathrm{T}(26,92,354)\end{array}$ \\
\hline
\end{tabular}

et al. (2005), and Lewis et al. (2016). The $K_{O C}$ ranges are based on the literature for each solute and a triangular law is applied to those values (Durkin, 2010, Van Scoy and Tjeerdema, 2014, Lauvernet and Muñoz Carpena, 2018).

\subsubsection{Sensitivity analysis results}

The sensitivity of soil water flow is assessed at 3 different times corresponding to the end of the dry, wet, and recovery periods of the experiment (Table 1 . Figure 6). The water table recharge volume, which represents the cumulative amount of water moving from the unsaturated to the saturated zone, allows examining more in detail the unsaturated zone hydraulic behavior. As expected, the reaction parameters $\left(K_{O C}\right.$ and $\left.\lambda\right)$ do not have influence on the hydrological variables, since they are not used in the soil water flow equations. $K_{s h}$, $K_{s v}$, and $n$ emerge as having linear effects (high values on the horizontal axis) but also nonlinear effects (high values on the vertical axis) on the water table recharge volume. At $25 \mathrm{~h}, I C$ (the rain conditioning the initial steady-state pressure) and $\theta_{s}$ also have an influence, but only during the first period. We note that $n$, which is related to the pore size distribution, has more influence in dry contexts. In all cases, results indicate an interaction between both horizontal and vertical conductivities. Contrary to the porosity and to the retention curve parameter $n, \alpha$ has a negligible effect on this output. 


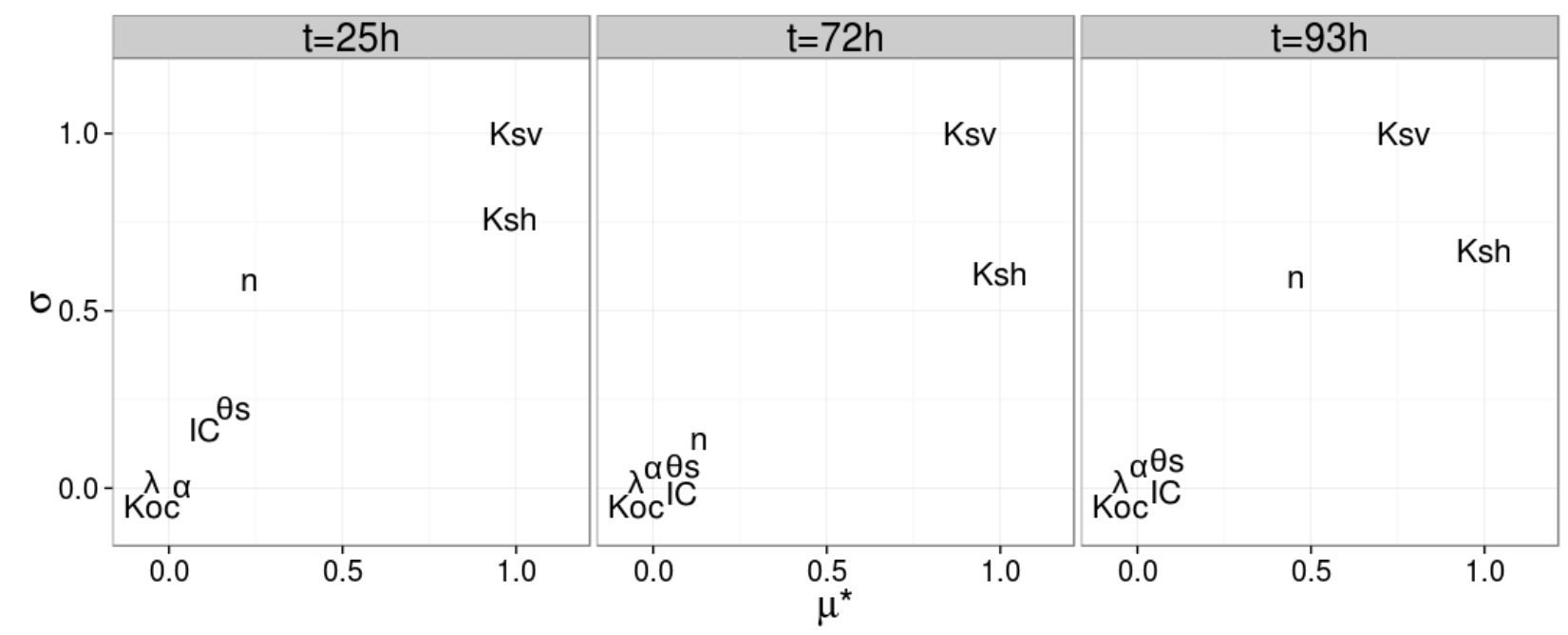

Figure 6: Morris sensitivity analysis results on the water table recharge volume at three times : at the end of the dry period $(t=25 \mathrm{~h})$, at the end of the wet period $(t=72 \mathrm{~h})$, and at the end of the recovery period $(t=93 \mathrm{~h})$. $\mu *$ is the absolute mean and $\sigma$ the standard deviation of elementary effects.

The sensitivity analysis results for reactive solute transport are presented in Figure 7 for clomazone and imazamox (batch 1) and for isoproturon and mesosulfuron (batch 2), considering four integrative output variables: breakthrough timing, peak timing, peak concentration, and NSE value relative to the output mass flow compared to observed data. The four dominant parameters for the recharge volume $\left(K_{s h}, K_{s v}, \theta_{s}\right.$, and $n$ ) also play an important role in solute transfer. In addition to these hydrological parameters, the sorption coefficient $K_{O C}$ has a major influence on these four outputs, especially for the breakthrough and peak timing. This confirms that the delay observed in initial simulations (see Figure 5 may be largely due to unadapted $K_{O C}$ values in this context. For $I C$ and $\alpha$, on the other hand, the elementary effects are negligible for all outputs and solutes. $\lambda$ has a linear effect for the NSE of isoproturon and imazamox in this context of short term simulation, being negligible for other molecules and outputs.

\subsection{Improvement of the CATHY model parameter settings}

The NSE index on mass flow is used as an indicator of the most efficient parameter sets (Figure 8). The selected combination is coherent across solutes, which suggests that the model is not overparameterized. In the top five NSE values, one parameter set is the same for three of the four solutes : clomazone, imazamox, and isoproturon (in red Figure 8), and one parameter set is the same for the four solutes (in blue Figure 8). The blue parameter set was then used to simulate the two solutes in batch 3 , bentazone and sulcotrione, and the results are presented in Figure 9 as a subsequent calibration.

Compared to the initial parameterization, the horizontal saturated conductivities and $K_{O C}$ are lower in this parameter set, whereas $n, K_{s v}, \theta_{s}$, and $\lambda$ are only slightly changed. The match between simulation and 


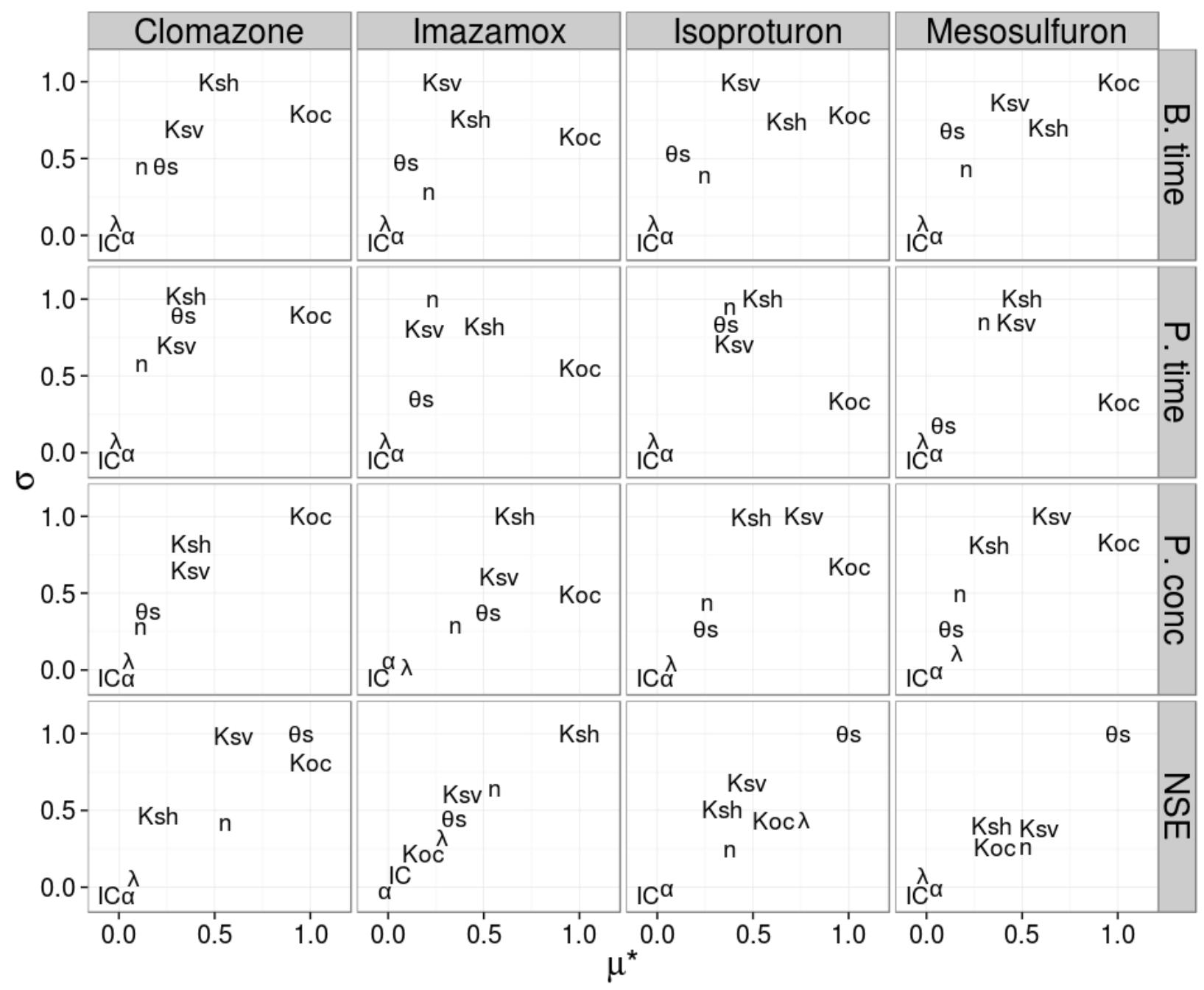

Figure 7: Morris sensitivity analysis results for clomazone and imazamox (batch 1) and isoproturon and mesosulfuron (batch 2) for four outputs: breakthrough timing (B. time), peak timing (P. time), peak concentration (P. conc) and NSE value relative to the output mass flow compared to observed data. $\mu *$ is the absolute mean and $\sigma$ the standard deviation of elementary effects.

data was much improved by the selection of this parameter set compared to the initial simulation (Figure 5). The simulated breakthrough timing is no longer delayed for sulcotrione, and less delayed for bentazone : the delay of $40 \mathrm{~h}$ originally has improved to a delay of $15 \mathrm{~h}$ with the optimal parameter set. In the chosen parameter set, $\theta_{s}, n$, and $\alpha$ define a retention curve that is lower in saturation for low pressure (under $-0.25 \mathrm{~m}$ ) than the original one, but gets closer of the original retention curve from $-0.25 \mathrm{~m}$ to 0 . This explains the breakthrough timing improvement despite the fact that porosity and saturated conductivities are not higher than the original ones. The selection of optimal parameters improved the evaluation quality and strongly decreased the associated uncertainty. Sulcotrione improved the most with an average NSE of 0.63, however the probability of the model fit being considered Unsatisfactory, Acceptable, Very good and Good, are $57.4 \%$, 


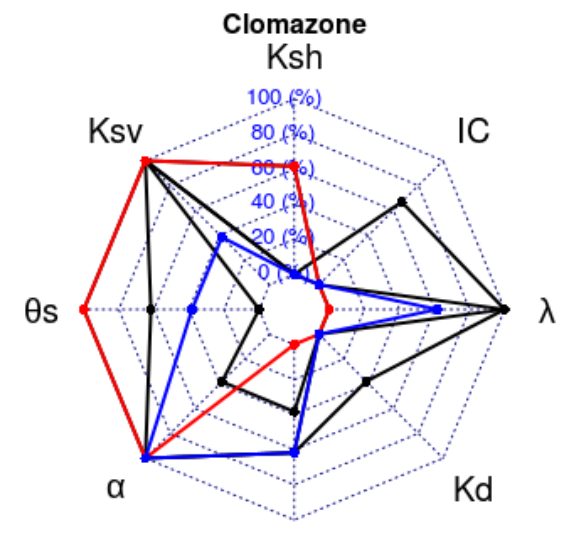

$\mathrm{n}$

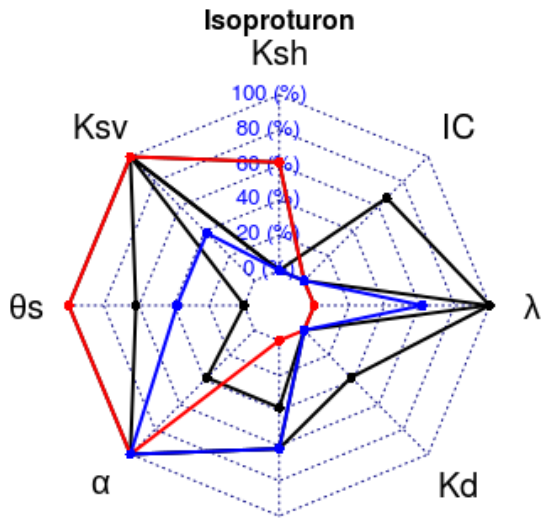

n
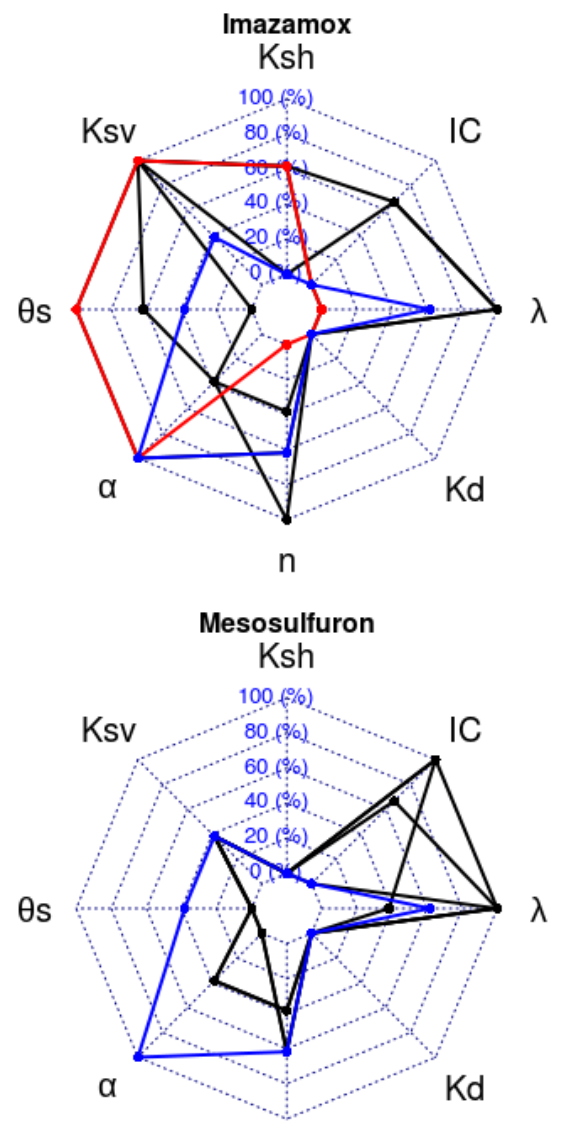

$\mathrm{n}$

Figure 8: Representation of the five best simulation sets from the Morris sampling for each solute, according to the NSE on mass flow. Parameter values are ranked between $0 \%$ and $100 \%$, which corresponds to the minimal and maximal values of each parameter distribution in the Morris sensitivity analysis. The red and blue combinations of parameters are the same, respectively, for clomazone, isoproturon and imazamox, and for the four solutes.

$33.7 \%, 5.3 \%$ and $3.6 \%$ respectively (see Table 8 ). 


\section{Bentazone}

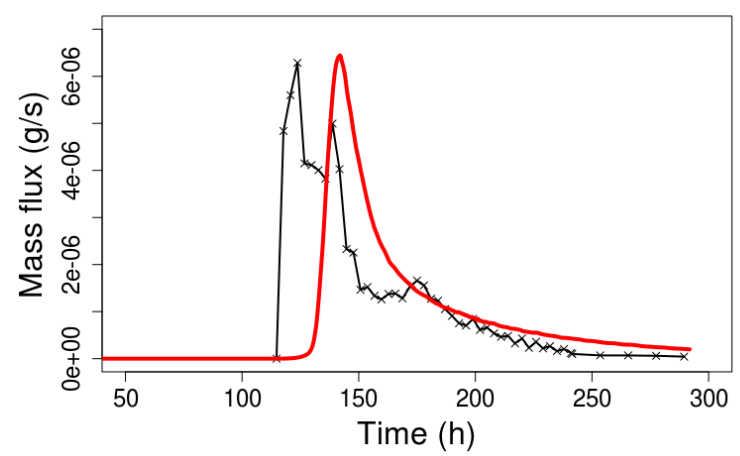

Sulcotrione

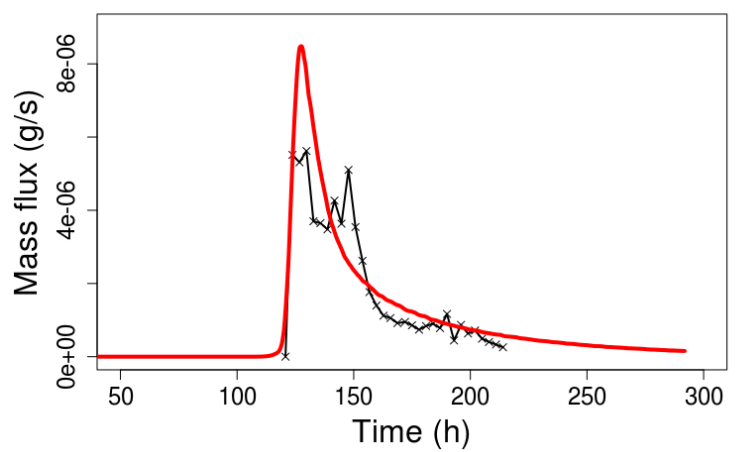

(a)

Figure 9: Results of output mass flow compared to measured data for batch 3 solutes. The simulations are performed here with the best parameter set resulting from the Morris sensitivity analysis.

Table 7: Performance of the reactive solute fluxes simulated with the best parameter set resulting from the Morris sensitivity analysis (95\% confidence intervals in brackets).

\begin{tabular}{|c|c|c|}
\hline & NSE & RMSE \\
\hline Bentazone & $-0.33[-0.943-0.846]$ & $1.8 e^{-6}\left[6.7 e^{-7}-3.0 e^{-6}\right]$ \\
\hline Sulcotrione & $0.63[0.486-0.892]$ & $1.0 e^{-6}\left[4.5 e^{-7}-1.5 e^{-6}\right]$ \\
\hline
\end{tabular}

\section{Conclusions}

In this study, the reactive transport version of the CATHY model is presented and evaluated in three steps. First, the model is evaluated on its ability to reproduce measured data from the MASHYNS laboratory experiment, without calibration, at three progressive levels: hydrological, nonreactive tracer, and reactive solute responses. The results show a satisfiying correspondance between observations and simulations for tracer breakthrough and a significant delay for reactive solute breakthrough. The performed evaluation is highly influenced by the delay and produces poor values for NSE, despite a coherent shape of mass output curves. For the solutes, four simulated mass balances out of six differ by more than $10 \%$ from the observed ones. In a second step, a Morris sensitivity analysis is performed for eight parameters and four solutes on the coupled flow and reactive transport model. Various outputs were taken into account, and five parameters emerge as particularly influential: the horizontal and vertical saturated conductivities $K_{s h}$ and $K_{s v}$, the porosity $\theta_{s}$, the retention curve parameter $n$, and the sorption coefficient $K_{O C}$. Although of these five factors only $K_{O C}$ is directly related to solutes, it is difficult to assess whether the first order decay parameter $\lambda$ is influential or not in this context due to its generally high value compared to the experiment duration, except for isoproturon. The sensitivity analysis brings out the robustness of the model with respect to parameter variations in this context, and highlights parameter interactions that are not easily discerned from the input parameterization. 
In the third step of the study, one efficient parameter set is chosen from the sensitivity analysis sampling based on the NSE value on output mass flow through time. This parameter set is applied to the two solutes that were not considered in the sensitivity analysis. The results in terms of evolution of output mass flow are improved: there is less or no more delay in the breakthrough timing and NSE values have increase.

This study demonstrated that the CATHY model is able to realistically reproduce experimental data with reactive solute transport at a small plot scale, after a calibration of its most influential parameters. It represents a solid first step in validating ISSHMs in a solute transport context, including problems of nonpoint source pollution in agriculture. In follow-up work we will upscale the study to the hillslope scale, and take into account surface/subsurface interactions.

\section{Supplementary material}

Table 8: NSE probability distribution (get by bootstrapping) and corresponding NSE statistical significance as defined in Ritter and Muñoz-Carpena (2013). 'After SA' lines correspond to the simulations performed with the best parameter set resulting from the Morris sensitivity analysis.

\begin{tabular}{|c|c|c|c|c|c|}
\cline { 3 - 6 } \multicolumn{1}{c|}{} & $\begin{array}{c}\text { Unsatisfactory } \\
\text { NSE }<0.65\end{array}$ & $\begin{array}{c}\text { Acceptable } \\
0.65<\mathrm{NSE}<0.80\end{array}$ & $\begin{array}{c}\text { Good } \\
0.80<\mathrm{NSE}<0.90\end{array}$ & $\begin{array}{c}\text { Very good } \\
0.90<\mathrm{NSE}\end{array}$ \\
\hline \multirow{2}{*}{ Wracers } & Amino-G & $76.7 \%$ & $38.2 \%$ & $36.3 \%$ & $5.8 \%$ \\
\cline { 2 - 6 } & Uranine & $94.4 \%$ & $4.8 \%$ & $2.8 \%$ & $0.6 \%$ \\
\hline \multirow{3}{*}{ Batch 1} & Clomazone & $100 \%$ & 0 & $0.8 \%$ & $0 \%$ \\
\cline { 2 - 6 } & Imazamox & $97 \%$ & $2.3 \%$ & $0.7 \%$ & 0 \\
\hline \multirow{3}{*}{ Batch 2 } & Isoproturon & $100 \%$ & 0 & 0 & 0 \\
\cline { 2 - 6 } & Mesosulfuron & $100 \%$ & 0 & 0 & 0 \\
\hline \multirow{3}{*}{ Batch 3 } & Bentazone & $100 \%$ & 0 & 0 & 0 \\
\cline { 2 - 6 } & Sulcotrione & $100 \%$ & 0 & $0.9 \%$ & $2.1 \%$ \\
\hline \multirow{2}{*}{ After SA } & Bentazone & $96.1 \%$ & $0.9 \%$ & $5.3 \%$ & $3.6 \%$ \\
\cline { 2 - 6 } & Sulcotrione & $57.4 \%$ & $33.7 \%$ & 0 & 0 \\
\hline
\end{tabular}

\section{References}

\section{References}

K. Aden and B. Diekkrüger. Modeling pesticide dynamics of four different sites using the model system SIMULAT. Agricultural Water Management, 44(1-3):337-355, 2000. doi: 10.1016/S0378-3774(99)00099-2. 
L. Ahuja, K. Rojas, J. Hanson, and M. Shaffer. Root Zone Water Quality Model: Modelling Management Effects on Water Quality and Crop Production. Water Resources Publications, Highlands Ranch, CO, 1999.

L. Alletto, V. Pot, S. Giuliano, M. Costes, F. Perdrieux, and E. Justes. Temporal variation in soil physical properties improves the water dynamics modeling in a conventionally-tilled soil. Geoderma, 243-244:18-28, 2015. doi: 10.1016/j.geoderma.2014.12.006.

Aquanty Inc. HydroGeoSphere User Manual. Waterloo, Ontario, Canada., 2015.

A. Armstrong, A. Matthews, A. Portwood, P. Leeds-Harrison, and N. Jarvis. CRACK-NP: a pesticide leaching model for cracking clay soils. Agricultural Water Management, 44(1-3):183-199, $2000 . \quad$ doi: 10.1016/S0378-3774(99)00091-8.

A. Boivin. Disponibilité spatio-temporelle et transfert des pesticides dans le sol. $\mathrm{PhD}$ thesis, Vandoeuvre-lesNancy, INPL, 2003.

F. Campolongo, J. Cariboni, and A. Saltelli. An effective screening design for sensitivity analysis of large models. Environmental Modelling \& Software, 22(10):1509-1518, 2007. doi: 10.1016/j.envsoft.2006.10.004.

M. Camporese, C. Paniconi, M. Putti, and S. Orlandini. Surface-subsurface flow modeling with path-based runoff routing, boundary condition-based coupling, and assimilation of multisource observation data. Water Resources Research, 46(2):W02512, 2010. doi: 10.1029/2008WR007536.

C. Coutadeur, Y. Coquet, and J. Roger-Estrade. Variation of hydraulic conductivity in a tilled soil. European Journal of Soil Science, 53(4):619-628, 2002. doi: 10.1046/j.1365-2389.2002.00473.x.

P. R. Durkin. Imazamox : Human health and ecological risk assessment, final report. Technical report, Syracuse Environmental Research Associates, Inc., 2010.

G. A. Fox, R. Muñoz-Carpena, and G. J. Sabbagh. Influence of flow concentration on parameter importance and prediction uncertainty of pesticide trapping by vegetative filter strips. Journal of Hydrology, 384(1-2): 164-173, 2010. doi: 10.1016/j.jhydrol.2010.01.020.

H. V. Gupta, H. Kling, K. K. Yilmaz, and G. F. Martinez. Decomposition of the mean squared error and NSE performance criteria: Implications for improving hydrological modelling. Journal of Hydrology, 377(1-2): 80-91, 2009. doi: 10.1016/j.jhydrol.2009.08.003.

R. Harmel, P. Smith, K. Migliaccio, I. Chaubey, K. Douglas-Mankin, B. Benham, S. Shukla, R. MunozCarpena, and B. Robson. Evaluating, interpreting, and communicating performance of hydrologic/water quality models considering intended use: A review and recommendations. Environmental Modelling $\mathcal{G}$ Software, 57:40-51, 2014. doi: 10.1016/j.envsoft.2014.02.013. 
J. Herman, J. Kollat, P. Reed, and T. Wagener. Method of Morris effectively reduces the computational demands of global sensitivity analysis for distributed watershed models. Hydrology and Earth System Sciences, 17(7):2893-2903, 2013.

K. Holvoet, A. van Griensven, P. Seuntjens, and P. Vanrolleghem. Sensitivity analysis for hydrology and pesticide supply towards the river in SWAT. Physics and Chemistry of the Earth, 30:518-526, 2005. doi: 10.1016/j.pce.2005.07.006.

S. K. Jain and K. Sudheer. Fitting of hydrologic models: a close look at the Nash-Sutcliffe index. Journal of Hydrologic Engineering, 13(10):981-986, 2008. doi: 10.1061/(ASCE)1084-0699(2008)13:10(981).

S. K. Kampf and S. J. Burges. Parameter estimation for a physics-based distributed hydrologic model using measured outflow fluxes and internal moisture states. Water Resources Research, 43(12), 2007. doi: 10. 1029/2006WR005605.

J. M. Kohne, S. Kohne, and J. Simunek. A review of model applications for structured soils: a) water flow and tracer transport. Journal of Contaminant Hydrology, 104(1):4-35, 2009. doi: 10.1016/j.jconhyd.2008.10.002.

S. Kollet, M. Sulis, R. M. Maxwell, C. Paniconi, M. Putti, G. Bertoldi, E. T. Coon, E. Cordano, S. Endrizzi, E. Kikinzon, E. Mouche, C. Mügler, Y.-J. Park, J. C. Refsgaard, S. Stisen, and E. Sudicky. The integrated hydrologic model intercomparison project, IH-MIP2: A second set of benchmark results to diagnose integrated hydrology and feedbacks. Water Resources Research, 53(1):867-890, 2017. doi: 10.1002/2016WR019191.

S. J. Kollet and R. M. Maxwell. Integrated surface-groundwater flow modeling: A free-surface overland flow boundary condition in a parallel groundwater flow model. Advances in Water Resources, 29(7):945-958, 2006. doi: $10.1016 /$ j.advwatres.2005.08.006.

R. Kumar, L. Samaniego, and S. Attinger. Implications of distributed hydrologic model parameterization on water fluxes at multiple scales and locations. Water Resources Research, 49(1):360-379, 2013. doi: 10.1029/2012WR012195.

M. Larsbo and N. Jarvis. MACRO 5.0: a model of water flow and solute transport in macroporous soil: technical description. Department of Soil Sciences, Swedish University of Agricultural Sciences Uppsala, 2003.

M. Larsbo and N. Jarvis. Simulating solute transport in a structured field soil. Journal of Environmental Quality, 34(2):621-634, 2005. doi: 10.2134/jeq2005.0621.

C. Lauvernet and R. Muñoz Carpena. Shallow water table effects on water, sediment, and pesticide transport in vegetative filter strips - part 2: model coupling, application, factor importance, and uncertainty. Hydrology and Earth System Sciences, 22(1):71-87, 2018. doi: 10.5194/hess-22-71-2018. 
T. Lenhart, K. Eckhardt, N. Fohrer, and H.-G. Frede. Comparison of two different approaches of sensitivity analysis. Physics and Chemistry of the Earth, 27(9-10):645-654, 2002. doi: 10.1016/S1474-7065(02)00049-9.

K. A. Lewis, J. Tzilivakis, D. J. Warner, and A. Green. An international database for pesticide risk assessments and management. Human and Ecological Risk Assessment, 22(4):1050-1064, 2016. doi: 10.1080/10807039. 2015.1133242 .

R. W. Malone, L. R. Ahuja, L. Ma, R. Don Wauchope, Q. Ma, and K. W. Rojas. Application of the Root Zone Water Quality Model (RZWQM) to pesticide fate and transport: an overview. Pest Management Science, 60(3):205-221, 2004. doi: 10.1002/ps.789.

R. M. Maxwell, M. Putti, S. Meyerhoff, J.-O. Delfs, I. M. Ferguson, V. Ivanov, J. Kim, O. Kolditz, S. J. Kollet, M. Kumar, S. Lopez, J. Niu, C. Paniconi, Y.-J. Park, M. S. Phanikumar, C. Shen, E. A. Sudicky, and M. Sulis. Surface-subsurface model intercomparison: A first set of benchmark results to diagnose integrated hydrology and feedbacks. Water Resources Research, 50(2):1531-1549, 2014. doi: 10.1002/2013WR013725.

A. Mazzia and M. Putti. High order Godunov mixed methods on tetrahedral meshes for density driven flow simulations in porous media. Journal of Computational Physics, 208(1):154-174, 2005. doi: 10.1016/j.jcp. 2005.01.029.

R. H. McCuen, Z. Knight, and A. G. Cutter. Evaluation of the Nash-Sutcliffe efficiency index. Journal of Hydrologic Engineering, 11(6):597-602, 2006. doi: 10.1061/(ASCE)1084-0699(2006)11:6(597).

K. Müller, M. Deurer, H. Hartmann, M. Bach, M. Spiteller, and H.-G. Frede. Hydrological characterisation of pesticide loads using hydrograph separation at different scales in a German catchment. Journal of Hydrology, 273(1-4):1-17, 2003. doi: 10.1016/S0022-1694(02)00315-3.

M. D. Morris. Factorial sampling plans for preliminary computational experiments. Technometrics, 33(2): 161-174, 1991. doi: 10.1080/00401706.1991.10484804.

M. Muma, S. J. Gumiere, and A. N. Rousseau. Analyse de sensibilité globale du modèle CATHY aux propriétés hydrodynamiques du sol d'un micro-bassin agricole drainé. Hydrological Sciences Journal, 59(8):1606-1623, 2014. doi: $10.1080 / 02626667.2013 .843778$.

R. Muñoz-Carpena, J. E. Parsons, and J. W. Gilliam. Modeling hydrology and sediment transport in vegetative filter strips. Journal of Hydrology, 214(1-4):111-129, 1999. doi: 10.1016/S0022-1694(98)00272-8.

R. Muñoz-Carpena, G. A. Fox, and G. J. Sabbagh. Parameter importance and uncertainty in predicting runoff pesticide reduction with filter strips. Journal of Environmental Quality, 39(2):630-641, 2010. doi: $10.2134 /$ jeq2009.0300. 
R. Muñoz-Carpena, C. Lauvernet, and N. Carluer. Shallow water table effects on water, sediment and pesticide transport in vegetative filter strips: Part a. non-uniform infiltration and soil water redistribution. Hydrology and Earth System Sciences Discussions, 2017:1-32, 2017. doi: 10.5194/hess-2017-405.

J. Nash and J. Sutcliffe. River flow forecasting through conceptual models part i : discussion of principles. Journal of Hydrology, 10(3):282-290, 1970. doi: 10.1016/0022-1694(70)90255-6.

L. A. Pangle, S. B. DeLong, N. Abramson, J. Adams, G. A. Barron-Gafford, D. D. Breshears, P. D. Brooks, J. Chorover, W. E. Dietrich, K. Dontsova, et al. The Landscape Evolution Observatory: A large-scale controllable infrastructure to study coupled Earth-surface processes. Geomorphology, 244:190-203, 2015. doi: 10.1016/j.geomorph.2015.01.020.

T. Paris. Etude du transfert d'eau et de solutés dans un sol à nappe superficielle drainée artificiellement. $\mathrm{PhD}$ thesis, ENGREF (AgroParisTech), 2004.

D. Persicani. Pesticide leaching into field soils: sensitivity analysis of four mathematical models. Ecological Modelling, 84(1):265 - 280, 1996. doi: 10.1016/0304-3800(94)00136-7.

M. Rabiet, C. Margoum, V. Gouy, N. Carluer, and M. Coquery. Assessing pesticide concentrations and fluxes in the stream of a small vineyard catchment - effect of sampling frequency. Environmental Pollution, 158 (3):737-748, 2010. doi: 10.1016/j.envpol.2009.10.014.

A. Ritter and R. Muñoz-Carpena. Performance evaluation of hydrological models: Statistical significance for reducing subjectivity in goodness-of-fit assessments. Journal of Hydrology, 480:33-45, 2013. doi: 10.1016/j. jhydrol.2012.12.004.

A. Rubio, A. Zalts, and C. E. Hasi. Numerical solution of the advection-reaction-diffusion equation at different scales. Environmental Modelling ES Software, 23(1):90-95, 2008. doi: 10.1016/j.envsoft.2007.05.009.

A. Saltelli, S. Tarantola, F. Campolongo, and M. Ratto. Sensitivity Analysis in Practice: A Guide to Assessing Scientific Models. John Wiley \& Sons, 2004.

A. Saltelli, M. Ratto, S. Tarantola, and F. Campolongo. Sensitivity analysis for chemical models. Chemical Reviews, 105(7):2811-2828, 2005. doi: 10.1021/cr040659d. PMID: 16011325.

A. Saltelli, M. Ratto, T. Andres, F. Campolongo, J. Cariboni, D. Gatelli, M. Saisana, and S. Tarantola. Global Sensitivity Analysis: The Primer. John Wiley \& Sons, 2008.

A. Schwen, G. Bodner, P. Scholl, G. D. Buchan, and W. Loiskandl. Temporal dynamics of soil hydraulic properties and the water-conducting porosity under different tillage. Soil and Tillage Research, 113(2): 89-98, 2011. doi: 10.1016/j.still.2011.02.005. 
C. Scudeler, L. Pangle, D. Pasetto, G.-Y. Niu, T. Volkmann, C. Paniconi, M. Putti, and P. Troch. Multiresponse modeling of variably saturated flow and isotope tracer transport for a hillslope experiment at the Landscape Evolution Observatory. Hydrology and Earth System Sciences, 20(10):4061-4078, 2016a. doi: 10.5194/ hess-20-4061-2016.

C. Scudeler, M. Putti, and C. Paniconi. Mass-conservative reconstruction of Galerkin velocity fields for transport simulations. Advances in Water Resources, 94:470-485, 2016b. doi: 10.1016/j.advwatres.2016.06.011.

M. L. Sebben, A. D. Werner, J. E. Liggett, D. Partington, and C. T. Simmons. On the testing of fully integrated surface-subsurface hydrological models. Hydrological Processes, 27(8):1276-1285, 2013. doi: 10.1002/hyp. 9630.

G. Sheng, C. T. Johnston, B. J. Teppen, and S. A. Boyd. Potential contributions of smectite clays and organic matter to pesticide retention in soils. Journal of Agricultural and Food Chemistry, 49(6):2899-2907, 2001. doi: $10.1021 /$ jf001485d.

J. Simunek, M. T. van Genuchten, and M. Sejna. The HYDRUS-1D software package for simulating the one-dimensional movement of water, heat, and multiple solutes in variably-saturated media. University of California-Riverside Research Reports, 3:1-240, 2005.

J. Simunek, M. T. van Genuchten, and M. Sejna. Development and applications of the HYDRUS and STANMOD software packages and related codes. Vadose Zone Journal, 7(2):587-600, 2008 . doi: 10.2136/vzj2007.0077.

I. M. Sobol. On sensitivity estimation for nonlinear mathematical models. Matematicheskoe Modelirovanie, 2 (1):112-118, 1990. doi: 1061-7590/93/04407-008.

M. T. van Genuchten. A closed-form equation for predicting the hydraulic conductivity of unsaturated soils. Soil Science Society of America Journal, 44(5):892-898, 1980.

A. R. Van Scoy and R. S. Tjeerdema. Environmental fate and toxicology of clomazone. In Reviews of Environmental Contamination and Toxicology. 2014.

S. Weill, A. Mazzia, M. Putti, and C. Paniconi. Coupling water flow and solute transport into a physicallybased surface-subsurface hydrological model. Advances in Water Resources, 34(1):128 - 136, 2011. doi: 10.1016/j.advwatres.2010.10.001.

J. Zhou, G. Cheng, X. Li, B. X. Hu, and G. Wang. Numerical modeling of wheat irrigation using coupled HYDRUS and WOFOST models. Soil Science Society of America Journal, 76(2):648-662, 2012. doi: 10. $2136 /$ sssaj2010.0467. 